\title{
Eczema herpeticatum - was prädestiniert Atopiekranke?
}

Ein Eczema herpeticatum auf dem Boden einer atopischen Dermatitis kann einen schweren Verlauf bis zum letalen Ausgang nehmen. Schnelles Handeln ist daher gefragt, wie Priv.-Doz. Dr. Andreas Wollenberg, München, in Davos berichtete.

D as Eczema herpeticatum ist als Infektion eines Ekzems mit dem Herpes-simplex-Virus definiert. Besonders häufig sind die Virentypen F1 und F35 die Auslöser. Das Ekzem kann auch mehrfach auftreten - Wollenberg berichtete von einem Patienten, der bereits sieben Mal betroffen war.

\section{Charakteristisches klinisches Bild}

Typisch ist das klinische Bild mit monomorphen Bläschen, später monomorphen Pusteln. Die Herpesbläschen bleiben dabei im Bereich der Erytheme. Histologisch fallen im Bläschenausstrich mehrkernige Riesenzellen auf. Eine Virusanzucht zur Diagnosestellung dauert oft zu lange - da schnelles Handeln gefragt ist, sollte laut Wollenberg eher die Immunfluoreszenz als schnelleres Verfahren angewendet werden.

Die atopische Ekzemhaut bietet den Herpesviren bessere Ansatzpunkte zur Bindung als die gesunde Haut. Zudem fehlen ihr antivirale Peptide wie die Defensine sowie Interferon-produzierende

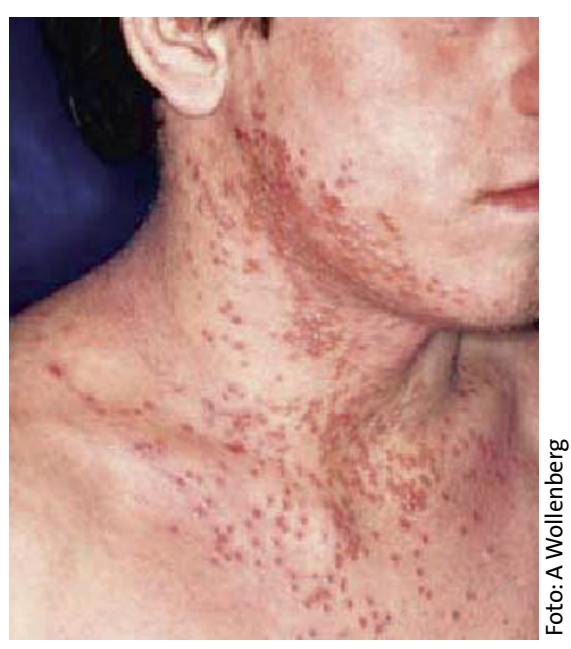

Ein Eczema herpeticatum kann auch mehrfach auftreten. plasmazytoide dendritische Zellen. Somit ist die Schwere des Infektionsverlaufs bei Neurodermitiskranken erklärlich.

Das Eczema herpeticatum tritt häufiger auf bei Patienten mit einem Beginn der Neurodermitis im frühem Lebensalter und einem hohen Gesamt-IgE-Spiegel im Serum. Die Therapie mit Glukokortikoiden stellt dagegen keinen Risikofaktor für ein Eczema herpeticatum dar - im Gegenteil: Wollenberg meint, dass eine effektive Neurodermitistherapie mit Glukokortikoiden eher ein Eczema herpeticatum vermeiden hilft. Unter der Therapie mit topischen Immunmodulatoren werden zwar geringfügig häufiger Virusinfekte beobachtet, ein Zusammenhang mit dem Eczema herpeticatum konnte aber bisher nicht gezeigt werden.

\section{Rasche Heilung durch antivirale Therapie}

Die Standardtherapie des Eczema herpeticatum stellt die systemische Gabe von Aciclovir i.v. dar, in leichten Fällen kann auch oral behandelt werden. Aciclovir kann auch gefahrlos in der Schwangerschaft gegeben werden. Als Alternative präferiert Wollenberg Valaciclovir, da es mit größerem Intervall verabreicht werden kann. Bei einer Keratitis sollte zusätzlich topisch antiviral behandelt werden. Als Begleittherapie kommen antiseptische Externa und gegebenenfalls auch orale Antibiotika wie Cefadroxil in Frage. Topische Immunmodulatoren sind in dieser Situation zu vermeiden. Die Therapie führt relativ schnell zur Krustenbildung und nach einer Woche bereits zu einem vollständigen Abheilen der Läsionen. $f k$

Wollenberg A. Eczema herpeticatum. 21. Fortbildungskongress „Fortschritte der Allergologie, Immunologie und Dermatologie“, Davos, 7.-10. September 2005 